\title{
Nystagmus may be the first neurological sign in early stages of spinocerebellar ataxia type 3
}

Nistagmo pode ser o primeiro sinal neurológico nos estágios precoces da ataxia espinocerebelar tipo 3

\author{
Maria Thereza Drumond GAMA', Flávio Moura REZENDE FILHO', Thiago Junqueira Ribeiro REZENDE², \\ Pedro BRAGA-NETO³, Marcondes Cavalcante FRANÇA JUNIOR², José Luiz PEDROSO', \\ Orlando Graziani Povoas BARSOTTINI ${ }^{1}$
}

\begin{abstract}
Background: Spinocerebellar ataxia type 3 (SCA3) is the most common autosomal dominant spinocerebellar ataxia worldwide. Almost all patients with SCA 3 exhibit nystagmus and/or saccades impairment. Objective:To investigate the presence of nystagmus as an early neurological manifestation, before ataxia, in some patients with SCA3 in the first six months of the disease. Methods: We evaluated a series of 155 patients with clinically and molecularly proven SCA3 between 2013 and 2020. Data regarding sex, age, age at onset, disease duration, CAG repeat expansion length, first symptom, presence of ataxia, scores on SARA and ICARS scales, and presence and characteristics of nystagmus were collected. Results: We identified seven patients with symptomatic SCA3 who presented with isolated nystagmus. In these seven individuals the age at onset ranged from 24 to 57 years, and disease duration from four to six months. Conclusions: Our study showed that nystagmus may be the first neurological sign in SCA3. This clinical observation reinforces the idea that the neurodegenerative process in SCA3 patients may start in vestibular system connections or in flocculonodular lobe. This study adds relevant information about pre-symptomatic features in SCA3 that may work as basis for a better understanding of brain degeneration and for future therapeutic clinical trials.
\end{abstract}

Keywords: Machado-Joseph Disease; Ataxin-3; Neurodegenerative Diseases; Cerebellar Ataxia.

\section{RESUMO}

Antecedentes: A ataxia espinocerebelar tipo 3 (SCA3) é a ataxia espinocerebelar de herança autossômica dominante mais comum em todo o mundo. Quase todos os pacientes com SCA3 têm nistagmo e/ou comprometimento das sácades. Objetivo: Investigar a presença de nistagmo como manifestação neurológica precoce, antes do surgimento da ataxia, em alguns pacientes com SCA3 nos primeiros seis meses de doença. Métodos: Foram avaliados 155 pacientes com diagnóstico clínico e molecular de SCA3, entre 2013 e 2020, em relação a sexo, idade, idade de início, duração da doença, expansão da repetição CAG, primeiro sintoma, presença de ataxia, pontuações nas escalas SARA e ICARS, e presença e caracterização de nistagmo. Resultados: Identificamos sete pacientes com SCA3 que apresentavam nistagmo isolado. A idade de início da doença nesses pacientes variou de 24 a 57 anos e a duração da doença variou de quatro a seis meses. Conclusões: O nosso estudo mostrou que o nistagmo pode ser o primeiro sinal neurológico na SCA3. Essa observação clínica reforça a ideia de que o processo neurodegenerativo nos pacientes com SCA3 pode se iniciar nas conexões do sistema vestibular ou no lobo floculonodular. Este estudo adiciona informações relevantes sobre características pré-sintomáticas na SCA3 e que podem servir de base para melhor entendimento da degeneração cerebral e para futuras terapias.

Palavras-chave: Doença de Machado-Joseph; Ataxina-3; Doenças Neurodegenerativas; Ataxia Cerebelar.

\section{INTRODUCTION}

Spinocerebellar ataxia type 3 (SCA3) is an abnormal CAG repeat expansion of the ATXN3 gene, located on chromosome $14 q^{1,2}$ and the most common autosomal dominant spinocerebellar ataxia worldwide. The typical phenotype is characterized by progressive cerebellar ataxia associated with nystagmus, other oculomotor abnormalities, pyramidal signs, and variable degrees of movement disorders, including parkinsonism and dystonia ${ }^{3}$. Symptoms usually start in

${ }^{1}$ Universidade Federal de São Paulo, Departamento de Neurologia, Unidade de Ataxia, São Paulo SP, Brazil.

Universidade de Campinas, Departamento de Neurologia, Campinas SP, Brazil.

${ }^{3}$ Universidade Federal do Ceará, Departamento de Neurologia, Fortaleza CE, Brazil.

MTDG (ID https://orcid.org/0000-0002-4414-0107; FMRF (iD https://orcid.org/0000-0003-4565-5898; TJRR (iD) https://orcid.org/0000-0001-8453-0313; PBN (D) https://orcid.org/0000-0001-9186-9243; MCFJ (iD https://orcid.org/0000-0003-0898-2419; JLP (iD) https://orcid.org/0000-0002-1672-8894; OGPB (iD) https://orcid.org/0000-0002-0107-0831

Correspondence: José Luiz Pedroso; Email: jlpedroso.neuro@gmail.com.

Conflict of interest: There is no conflict of interest to declare.

Authors' contributions: MTDG, FMRF, TJRR, PBN, JLP: article project (conception, organization and execution), writing of the first draft and review and critique; MCFJ, OGB: article project (conception, organization and execution), review and critique of the manuscript.

Received on November 04, 2020; Received in its final form on December 20, 2020; Accepted on December 22, 2020. 
the fourth or fifth decade of life, although early $\mathrm{r}$ and late onset may occur depending on the CAG repetition length. Larger CAG repetition lengths are associated with genetic anticipation and earlier disease onset ${ }^{4}$.

Several authors have postulated that SCA3 should be divided into specific phenotypes depending on age of onset. Patients with early onset, in the second or third decade of life, present with marked extrapyramidal features (parkinsonism and dystonia) and a more severe disease, while patients with adult onset usually present with cerebellar ataxia associated with pyramidal signs. On the other hand, patients with very late onset present with slow progression and a less severe phenotype ${ }^{5}$. However, the criticism raised on the classification into phenotypes is that clinical features may vary in different stages with disease progression. Therefore, patients with early onset may present with pure cerebellar ataxia in the first years, and a severe parkinsonism and dystonia may occur in advanced stages ${ }^{5}$.

Besides ataxia, nystagmus is one the most common neurological feature observed in patients with SCAs. Almost all patients with SCA3 present with nystagmus or/and saccades impairment ${ }^{6}$. Nystagmus in SCA3 is usually spontaneous and symmetrical, and may be vertical or horizontal. Nystagmus is anatomically related to the vestibular system (peripheral or central) ${ }^{6,7}$. Pathological and functional studies in SCA3 have demonstrated involvement of the vestibular system and its connections. Moreover, the flocculonodular lobe has important connections with vestibular nuclei ${ }^{6,7,8}$. Thus, flocculonodular lobe involvement in SCA3 may partially explain nystagmus as a very common neurological sign in SCA3.

In this article we aimed to demonstrate if nystagmus could be an early neurological manifestation, before ataxia, in patients with SCA3 in the first 6 months of the disease. Also, we discuss the natural history of brain degeneration in SCA3, and postulate that flocculonodular lobe and vestibular system (and its connections) are the first structures involved in brain degeneration of these patients.

\section{METHODS}

From a series of 155 patients with clinically and molecularly proven SCA3, we evaluated seven patients in the first six months of disease duration, between 2013 and 2020. Many patients with SCA3 from this series were firstly evaluated in different stages of the disease, and already presented with ataxia in the first appointment. Sex, age, age at onset, disease duration, CAG repeat expansion length, first symptom, presence of ataxia, scores on SARA and ICARS scales, and presence and characterization of nystagmus in all 7 patients were recorded. Subjects with SCA3 and pure nystagmus also underwent brain magnetic resonance imaging.

\section{RESULTS}

In these seven individuals with symptomatic SCA3 and pure nystagmus, the age at onset ranged from 24 to 57 years, and disease duration from four to six months. Their SARA score was zero and ICARS score was 1 . CAG repetition number varied from 61 to 80 and cerebellar atrophy in MRI was seen in two out of seven individuals. In all cases, the nystagmus was gaze-evoked, horizontal and vertical, mild and transitory, not accompanied by saccadic pursuit, dysmetric saccades, or ophthalmoparesis. Their first symptom was either loss of balance or dizziness. The clinical and molecular profiles of SCA3 patients with isolated nystagmus are showed in Table 1. From the seven patients described, two progressed to type 1 SCA3 phenotype (marked extrapyramidal features), three to type 2 (pure ataxia and pyramidal signs), and one developed type 3 (slow progressive ataxia and neuropathy).

\section{DISCUSSION}

In this article, we demonstrated that nystagmus may be the first neurological sign in some patients with SCA3. Neurological evaluation in the first months of symptoms disclosed no cerebellar sign in the seven patients with SCA3. The main questions discussed in this article are: Can patients with SCA3 in the first months of symptoms be misdiagnosed?; and should a genetic test for SCA3 be requested for a patient with positive family history and pure nystagmus as the first sign? Finally, the pathophysiological mechanisms related with pure nystagmus as the first sign indicate that flocculonodular lobe, its connections, or the vestibular system are the first structures to be damaged concerning the natural history of brain degeneration in patients with SCA3.

Similarly to the article by Raposo et al., our study suggests that in early stages, the neurodegenerative process in SCA3 predominantly affects the vestibular system and its cerebellar connections, before damage to the cerebellar neurons involved in gait and coordination becomes clinically relevant $^{7}$. Also, in line with our findings, Raposo et al. demonstrated nystagmus occurs in a considerable proportion of pre-symptomatic carriers of mutated ATXN3 alleles, which were tested for being relatives of SCA3 patients? ${ }^{7}$. Our study took place in a healthcare setting, thus showing that isolated nystagmus occurs in symptomatic SCA3 individuals in clinical practice.

Our cases had positive family history and they reported vague complains of either vertigo or dizziness by the time of their first evaluation. The decision to test for SCA3 was based on the presence of gaze-evoked nystagmus, which usually occurs in cerebellar conditions. Nystagmus can be subtle and may be overlooked, and it is possible that SCA3 cases with isolated nystagmus are misdiagnosed. Although it is neither 
Table 1. Summary of clinical features of patients with spinocerebellar ataxia type 3 and isolated nystagmus as initial presentation.

\begin{tabular}{|c|c|c|c|c|c|c|c|}
\hline $\begin{array}{l}\text { Case } \\
\text { number }\end{array}$ & Sex & $\begin{array}{l}\text { Age of disease } \\
\text { onset (years) }\end{array}$ & $\begin{array}{l}\text { Disease duration } \\
\text { (months) }\end{array}$ & SARA & ICARS & $\begin{array}{l}\text { CAG repetition } \\
\text { number }\end{array}$ & $\begin{array}{c}\text { MRI } \\
\text { findings }\end{array}$ \\
\hline 1 & Female & 24 & 3 & 0 & 1 & 80 & Normal \\
\hline 2 & Female & 56 & 6 & 0 & 1 & - & Not performed \\
\hline 3 & Male & 57 & 6 & 0 & 1 & 61 & Normal \\
\hline 4 & Male & 37 & 3 & 0 & 1 & 71 & Cerebellar atrophy \\
\hline 5 & Male & 39 & 4 & 0 & 1 & 67 & Cerebellar atrophy \\
\hline 6 & Male & 48 & 3 & 0 & 1 & - & Normal \\
\hline 7 & Male & 39 & 4 & 0 & 1 & - & Normal \\
\hline
\end{tabular}

ICARS: international cooperative ataxia rating scale; MRI: magnetic resonance imaging; SARA: scale for assessment and rating of ataxia; SCA3: spinocerebellar ataxia type 3.

ethically advisable nor cost-effective to test asymptomatic individuals at risk for SCA3, patients should undergo molecular investigation if they become symptomatic and exhibit objective neurological signs with no other apparent cause. Early diagnosis is important for implementing timely genetic counseling and physical rehabilitation, and for enrollment in therapeutic clinical trials.

Pre-motor symptoms have been discussed in several neurodegenerative diseases, such as Parkinson's disease, in which hyposmia and REM sleep disorder manifest several years before tremor and bradykinesia ${ }^{9}$. In SCA3, oculomotor dysfunction seems to precede the motor abnormalities in trunk and limbs and gait difficulty. Notably, all cases of SCA3 with isolated nystagmus in this study ultimately developed ataxia and other neurological signs. They progressed to ataxia with different phenotypes in the course of the disease. The progression from isolated nystagmus to classical SCA3 phenotypes is in line with Braak theory for Parkinson's disease, which supports that progressive spread of Lewy pathology to different structures of the nervous system leads to the summation of specific clinical features ${ }^{9,10,11}$. It is important to bear in mind that patients with pre-motor symptoms may constitute a relevant group for clinical trials and for a better understanding of natural history of brain degeneration?.

MRI-based studies have been very helpful in depicting the natural history of several diseases, including SCA3. Recently, Rezende et al. evaluated a large number of patients of SCA3 in different stages, including pre-symptomatic individuals, through a multimodal MRI in order to determine the extension and progression of central nervous system involvement. The authors demonstrated that damage initially affected the spinal cord, cerebellar peduncles, and substantia nigra, while in advanced stages it spread to cerebellar vermis and hemispheres, and other cerebral areas. Although that study presents a stage scheme to map the natural history of brain degeneration in SCA3, it was a retrospective and observational study and did not follow neuroanatomic changes overtime ${ }^{10}$. Longitudinal analyses are still scarce in SCA3 and, indeed, prospective approaches are still scarce in SCA3 $3^{11,12,13}$. Besides anatomical damage, Joers at al. showed that important metabolites, such as NAA/mI, NAA/Cr, and NAA/Cho, are reduced in the pons and cerebellum of pre-symptomatic individuals with SCA $3^{14}$. Indeed, all these MRI findings are in line with the manifestation of nystagmus in early stages of the disease and further analysis need to be done to confirm this hypothesis. Of note, three of the seven patients of our series with pure nystagmus and SCA3 had a normal conventional brain MRI, which suggests that this is not a reliable biomarker for neurological involvement in the beginning of the symptoms.

Nystagmus in cerebellar disorders results from dysfunction in cerebellar projections to the neural integrator, which is responsible for maintaining the position of gaze or gazeholding after saccades occur. Saccades are produced by the saccades generators, the rostral interstitial nucleus of medial longitudinal fasciculus (midbrain), which generates vertical saccades, and the pontine paramedian reticular formation and sixth nerve nucleus (pons), which generate horizontal saccades. Repetitive saccades are required to compensate for the deficit in gaze holding, and correspond to the fast phase of the nystagmus. Therefore, in SCA3 and other cerebellar conditions, failure to the neural integrator leads to gazeevoked nystagmus ${ }^{15,16}$.

There are limitations in our study. Firstly, the vast majority of patients with SCA3 in our Ataxia Unit were firstly evaluated after the second year of the disease onset, and many assessments were not performed in the first months of symptoms. Also, brain imaging was restricted to standard brain MRI, and a specific imaging protocol was not performed.

In conclusion, nystagmus can be the only neurological sign in symptomatic patients with SCA3 in early stages, which represent a small proportion of individuals seen in a neurogenetic outpatient clinic. Our findings reinforce the idea that the neurodegenerative process in SCA3 patients predominantly affects vestibular system connections or flocculonodular lobe early in disease course. Finally, our study indicates clinicians should look carefully for oculomotor abnormalities in individuals at risk for SCA3, which may ensure timely diagnosis, genetic counseling, and therapeutic interventions. 
1. Paulson H. Machado-Joseph disease/Spinocerebellar ataxia type 3. Handb Clin Neurol. 2012;103:437-49. https://doi.org/10.1016/B9780-444-51892-7.00027-9

2. Pedroso JL, Braga-Neto P, Radvany J, Barsottini OG. MachadoJoseph disease in Brazil: from the first descriptions to the emergence as the most common spinocerebellar ataxia. Arq NeuroPsiquiatr. 2012 Aug;70(8):630-32. https://doi.org/10.1590/S0004282X2012000800013

3. Nakano KK, Dawson DM, Spence A. Machado-Joseph disease. A hereditary ataxia in Portuguese emigrants to Massachusetts. Neurology. 1972 Jan;22(1):49-55. https://doi.org/10.1212/ wnl.22.1.49

4. Schöls L, Amoiridis G, Epplen JT, Langkafel M, Przuntek H, Riess O. Relations between genotype and phenotype in German patients with the Machado-Joseph disease mutation.J Neurol Neurosurg Psychiatry. 1996 Nov;61(5):466-70. https://doi.org/10.1136/ jnnp.61.5.466

5. Moro A, Munhoz RP, Arruda WO, Raskin S, Moscovich M, Teive HA. Spinocerebellar ataxia type 3: subphenotypes in a cohort of Brazilian patients. Arq Neuro-Psiquiatr. 2014 Sep;72(9):659-62. https://doi. org/10.1590/0004-282×20140129

6. Rüb U, Brunt ER, de Vos RA, Del Turco D, Del Tredici K, Gierga K, et al. Degeneration of the central vestibular system in spinocerebellar ataxia type 3 (SCA3) patients and its possible clinical significance. Neuropathol Appl Neurobiol. 2004 Aug;30(4):402-14. https://doi. org/10.1111/j.1365-2990.2004.00554.X

7. Raposo M, Vasconcelos J, Bettencourt C, Kay T, Coutinho P, Lima M. Nystagmus as an early ocular alteration in Machado-Joseph disease (MJD/SCA3). BMC Neurol. 2014 Jan;14:17. https://doi. org/10.1186/1471-2377-14-17

8. Ribeiro RS, Pereira MM, Pedroso JL, Braga-Neto P, Barsottini OG, Manzano GM. Cervical and ocular vestibular evoked potentials in Machado-Joseph disease: functional involvement of otolith pathways. J Neurol Sci. 2015 Nov;358(1-2):294-8. https://doi. org/10.1016/j.jns.2015.09.013

9. Pedroso JL, Bor-Seng-Shu E, Braga-Neto P, Ribeiro R, Bezerra ML, Prado LB, et al. Neurophysiological studies and non-motor symptoms prior to ataxia in a patient with Machado-Joseph disease: trying to understand the natural history of brain degeneration. Cerebellum. 2014 Aug;13(4):447-51. https://doi.org/10.1007/s12311-014-0553-8

10. Rezende TJ, Paiva JL, Martinez AR, Cendes IL, Pedroso JL, Barsottini $\mathrm{OG}$, et al. Structural signature of SCA3: from presymptomatic to late disease stages. Ann Neurol. 2018 Sep;84(3):401-8. https://doi. org/10.1002/ana.25297

11. D’Abreu A, França-Jr MC, Yasuda CL, Campos BA, Cendes IL, Cendes F. Neocortical atrophy in Machado-Joseph disease: a longitudinal neuroimaging study.J Neuroimaging. 2012 Jul;22(3):285-91. https:// doi.org/10.1111/j.1552-6569.2011.00614.x

12. Reetz K, Costa AS, Mirzazade S, Lehmann A, Juzek A, Rakowicz M, et al. Genotype-specific patterns of atrophy progression are more sensitive than clinical decline in SCA1, SCA3 and SCA6. Brain. 2013 Mar;136(Pt 3):905-17. https://doi.org/10.1093/brain/aws369

13. Adanyeguh LM, Perlbarg V, Henry PG, Rinaldi D, Petit E, Valabregue $\mathrm{R}$, et al. Autosomal dominant cerebellar ataxias: imaging biomarkers with high effect sizes. Neuroimage Clin. 2018 Jun;19:858-67. https:// doi.org/10.1016/j.nicl.2018.06.011

14. Joers JM, Deelchand DK, Lyu T, Emir UE, Hutter D, Gomez CM, et al. Neurochemical abnormalities in premanifest and early spinocerebellar ataxias. Ann Neurol. 2018 Apr;83(4):816-29. https:// doi.org/10.1002/ana.25212

15. Campbell W. The Oculomotor Nerves: Dejong's The Neurologic Examination. $7^{\text {th }}$ ed. Philadelphia: Lippincott Williams \& Wilkins; 2013.

16. Kheradmand A, Zee DS. Cerebellum and ocular motor control. Front Neurol. 2011 Sep;2:53. https://doi.org/10.3389/fneur.2011.00053 